\title{
Quando o acesso é o menor dos problemas: o direito ao espaço escolar de qualidade
}

When access is the least of the problems: the right to quality school space

Rosimar Serena Siqueira Esquinsani

Doutora em Educação

Programa de Pós-Gradução em Educação - Universidade de Passo Fundo/UPF rosimaresquinsani@upf.br

\begin{abstract}
Resumo
O texto parte da seguinte premissa: conquistar uma vaga na escola pública é parte do direito à educação, mas tal direito só estará completo se a vaga se fizer acompanhada por referenciais de qualidade, entre os quais, uma infraestrutura adequada. Para problematizar a qualidade do espaço escolar, apresenta como pano de fundo, parte dos dados publicizados pela pesquisa da UNESCO (ALVES; XAVIER, 2019) sobre a infraestrutura das escolas. Metodologicamente, trata-se de um texto analítico-reconstrutivo de base bibliográfica (revisão temática), cotejado por informações censitárias. O texto coloca a questão da qualidade, na educação, como um tema político, que perpassa por espaços adequados, com o mínimo de infraestrutura, higiene e segurança. Conclui que a consecução de um direito não está descolada de condições contextuais e objetivas que garantam sua efetividade, para além de declarações e intenções. Portanto, é preciso ir além da vaga: garantir a permanência, o sucesso escolar e um padrão mínimo (digno) de qualidade na escola.
\end{abstract}

Palavras-chave: Direito à educação. Escola pública. Espaço escolar. Infraestrutura. Qualidade.

\begin{abstract}
The text starts from the following premise: winning a place in the public school is part of the right to education, but that right will only be complete if is accompanied by quality references, among which, an adequate infrastructure. To problematize the quality of the school space, it presents as a backdrop, part of the data published by UNESCO research (ALVES; XAVIER, 2019) on the infrastructure of schools. Methodologically, it is an analytical-reconstructive text with a bibliographic basis (thematic review), and census information. The text poses the issue of quality, in education, as a political theme, which runs through adequate spaces, with a minimum of infrastructure, hygiene and safety. It concludes that the achievement of a right is not detached from contextual and objective conditions that guarantee its effectiveness, beyond declarations and intentions. Therefore, it is necessary to go beyond the vacancy: guarantee permanence, academic success and a minimum (dignified) standard of quality in the school.
\end{abstract}

Key-words: Right to education. Public school. School space. Infrastructure. Quality.

O direito à educação, garantido por inúmeros dispositivos jurídico-normativos respaldados pela Constituição Federal de 1988, não prospecta, necessariamente, uma relação direta entre tal direito e a qualidade da sua oferta. Tal descompasso constitui cenário acerca do qual ocorrem 
reações que se processam em, no mínimo, duas perspectivas: por um lado, há esforços empenhados pelos agentes públicos - em diferentes esferas -, para a materialização de políticas públicas que garantam a qualidade na educação e, por outro lado, há um intenso movimento acadêmico, adensando pesquisas e discussões sobre qualidade na/da educação.

O texto apresentado é resultado desta segunda perspectiva: propõe uma leitura do fenômeno a partir de uma pesquisa empírica e de ancoragens teóricas que versam sobre a educação como um direito. Propõe uma leitura sobre a democratização do acesso à educação, ponderando acerca da qualidade ofertada em escolas públicas, na medida em que apresenta como pano de fundo, parte dos dados publicizados pela pesquisa da UNESCO (ALVES; XAVIER, 2019) sobre a infraestrutura das escolas.

Toma como ponto de partida a seguinte premissa: uma vez que a educação é um direito (CF, art. 205), todos os esforços erigidos no sentido de garantir a qualidade, na educação, (seja através de políticas, indicadores ou apropriações teórico-conceituais) são considerados instrumentos assertivos visando assegurar esse direito, pois a qualidade na educação é pressuposto elementar para consecução plena de tal direito. Isto porque:

O direito à educação não pode ser confundido com o direito ao acesso à escola, traduzido pelo aumento das estatísticas dos alunos matriculados, apenas. Este acesso precisa vir acompanhado do compromisso com a aprendizagem dos estudantes e com seu direito de acesso ao conhecimento acumulado (SORDI; LUDKE, 2009, p. 328).

Metodologicamente, o texto estruturou-se a partir da problematização de alguns dados da pesquisa referida, cotejados por outros dados censitários e ponderados a partir de uma pesquisa bibliográfica, utilizando metodologia analítico-reconstrutiva, materializada através da descrição, categorização, exame e reconstrução de argumentos.

Por fim, cumpre informar que o texto apresentado faz parte dos resultados parciais de uma pesquisa que objetiva estabelecer marcos de qualidade para a educação em redes e sistemas públicos de ensino, bem como os elementos de composição da atual agenda educacional.

\section{Problematizando a qualidade do espaço escolar}

A Constituição Federal de 1988 garante a educação na esfera dos direitos (art. 205, BRASIL, 1988), mas, também, menciona os princípios que orientam, efetivamente, o acesso a tal direito, informando a "...garantia de padrão de qualidade" (Art. 206, inciso VIII). A multiplicidade de fatores que compõem tal padrão de qualidade podem direcionar as mais variadas reflexões. 
Todavia, no texto em tela, o foco recai sobre a infraestrutura das escolas e seu emparelhamento com qualidade.

\begin{abstract}
A infraestrutura física, assim como os recursos pedagógicos são importantes e precisam ser considerados na concepção da escola como um espaço de dignidade e respeito. O direito à educação é algo bem mais amplo que o direito à escola. [...]. Nos prédios escolares, mais do que em qualquer outro espaço, é fundamental que os equipamentos, o mobiliário e as dimensões dos ambientes estejam adequados às necessidades das pessoas que os utilizam, contribuindo favoravelmente ao desempenho dos alunos, tanto em termos de saúde como em termos de aprendizagem (FRANÇA, et al., 2012, p. 89).
\end{abstract}

O Plano Nacional de Educação - Lei 13.005/2014 - apresenta, na Meta 7, uma estratégia voltada para a narrativa do que seria considerado básico, em termos de infraestrutura:

7.18. assegurar a todas as escolas públicas de educação básica o acesso a energia elétrica, abastecimento de agua tratada, esgotamento sanitário e manejo dos resíduos sólidos, garantir o acesso dos alunos a espaços para a pratica esportiva, a bens culturais e artísticos e a equipamentos e laboratórios de ciências e, em cada edifício escolar, garantir a acessibilidade as pessoas com deficiencia (BRASIL, 2014).

A legislação brasileira apenas reverbera indicações advindas da pesquisa científica, que estabelece relação direta entre a infraestrutura das escolas e o desempenho de aprendizagem dos alunos (BID, 2011). Portanto, amiudar e problematizar a infraestrutura escolar, como elemento essencial na busca por uma qualidade educacional, pode auxiliar (ou, ao menos, enfatizar) na percepção do espaço escolar como um dos elementos relevantes na composição da qualidade.

Em 2019, entretanto, à despeito de toda retórica em torno do acesso e da qualidade na educação, a UNESCO - Organização das Nações Unidas para a Educação, a Ciência e a Cultura publicou, em parceria com a Universidade Federal de Minas Gerais (UFMG) e em cooperação do Ministério da Educação, pesquisa onde expõe um conjunto de indicadores de infraestrutura das escolas brasileiras, sob coordenação das professoras Maria Teresa Gonzaga Alves e Flavia Pereira Xavier.

De tal modo, o texto parte dos dados publicizados pela pesquisa reportada, (ALVES; XAVIER 2019) sobre a infraestrutura das escolas, problematizando a questão da qualidade na educação como um tema político, que perpassa por espaços adequados, com o mínimo de infraestrutura, higiene e segurança.

A pesquisa referida aponta cinco dimensões de avaliação da infraestrutura das escolas, sendo as mesmas: a) dimensão área; b) dimensão atendimento; c) dimensão condições do estabelecimento de ensino; d) dimensão condições para o ensino e aprendizado e, e) dimensão condições para a equidade (ALVES; XAVIER 2019, pp. 36-37). Além dessas dimensões, a 
pesquisa apresenta, ainda, um total de 11 (onze) indicadores: Serviços básicos; Instalações do prédio; Prevenção de danos; Conservação; Conforto; Ambiente prazeroso; Espaços pedagógicos; Equipamento para apoio administrativo; Equipamento para apoio pedagógico; Acessibilidade e Ambiente para AEE, sintetizados pelo indicador Infraestrutura geral (ALVES; XAVIER 2019), como métricas de infraestrutura das escolas públicas, nas dependências federal, estadual e municipal, bem como das escolas privadas.

Alguns dos resultados endereçados, na pesquisa, mostram que, quando comparados os indicadores, os melhores resultados - em todos os indicadores e em série histórica - são registrados nas escolas públicas federais, com médias que chegam a triplicar em alguns pontos, quando confrontadas com as demais dependências, como nos indicadores 'conforto', 'espaços pedagógicos’ e 'equipamentos para apoio administrativo' (ALVES; XAVIER 2019, p.40).

Comparativamente, o maior défcit de infraestrutura foi registrado nas escolas públicas municipais, com alguns indicadores que apresentam resultados muito inferiores às demais escolas. Tal informação é referendada pelo Gráfico 01 'Evolução do indicador geral de infraestrutura escolar por dependência administrativa, total e ano’ (ALVES; XAVIER 2019, p. 41), onde a média das redes municipais está, inclusive, abaixo das médias acumuladas entre as quatro dependências examinadas.

O Brasil apresentou um total de 47.874.246 matrículas na Educação Básica, em 2019 (BRASIL, 2020). As matrículas vinculadas às escolas da dependência administrativa municipal são as mais numerosas e totalizam 23.027.621 matrículas, ou 48,1\% do total de matrículas. Assim, se considerarmos que a maior parte das matrículas está alocada em escolas públicas municipais, parece pouco producente outras dependências administrativas (mormente federal e privada) apresentarem métricas positivas, se a maior parte dos alunos da educação básica brasileira está matriculada em escolas municipais, sujas métricas de infraestrutura apresentada pelo relatório são baixas.

Sequencialmente, a pesquisa reportada expõe dados sobre a 'Distribuição das médias dos indicadores por total de escolas estaduais e municipais de ensino fundamental, localização da escola e edição da pesquisa' (ALVES; XAVIER 2019, p.42), centrando dados em escolas públicas das redes estaduais e municipais de educação básica. Enquanto a dependência administrativa municipal responde por 48,1\% do total de matrículas - como já referido -, as escolas vinculadas a dependência estadual somam 15.307.033 matrículas. Juntas, as duas dependências (estadual e municipal) somam 38.334.654 matrículas, ou seja, 80\% do total de matrículas (BRASIL, 2020).

Até aqui, as constatações da pesquisa referendam a percepção de Oliveira e Araújo no que tange ao direito à educação... 
Apesar da ampliação do acesso à etapa obrigatória de escolarização observada nas últimas décadas, o direito à educação tem sido mitigado pelas desigualdades, tanto sociais quanto regionais. Isso inviabiliza a efetivação dos dois outros princípios basilares da educação entendida como direito: a garantia de permanência e sucesso na escola com nível de qualidade equivalente para todos. (OLIVEIRA; ARAÚJO, 2005, p. 13).

A pesquisa aponta, ainda (ALVES; XAVIER 2019, p.46), que os indicadores de infraestrutura, nos anos iniciais do Ensino Fundamental (primeira etapa ou Fundamental I), são menores em relação aos anos finais do ensino fundamental (segunda etapa ou Fundamental II). Nos onze indicadores, na síntese e na série histórica, o resultado dos anos finais do ensino fundamental é melhor ou superior aos resultados dos indicadores dos anos iniciais. Ocorre que o país apresentou, em 2019, 26.923.730 matrículas no Ensino Fundamental (BRASIL, 2020), sendo 15.018.498 nos anos iniciais e 11.905.232 matrículas nos anos finais do ensino fundamental (segunda fase, ou fundamental II). Novamente, aqui a infraestrutura deficitária atingiria, em tese, a mais de $50 \%$ das crianças matriculadas.

\section{Outros dados sobre a qualidade do espaço escolar}

A imagem de uma precária infraestrutura, em escolas públicas de educação básica, é, constantemente, construída e reforçada pela mídia. É, suficientemente, comum a vinculação de denúncias acerca das condições prediais ou da ausência de insumos básicos em escolas públicas. Se considerarmos a pesquisa de Alves e Xavier, podemos inferir que há materialidade para tal imagem.

Para ilustrar os dados interpretados, a partir da pesquisa de Alves e Xavier, assim como para dar materialidade aos argumentos em torno da qualidade da educação como um direito, realizamos um levantamento amostral de reportagens em mídias locais (jornais/revistas de circulação local), ao longo do ano de 2019, que indicassem condições de infraestrutura de escolas.

A pesquisa foi realizada em sites de pesquisa na internet (Google; Yahoo e Bing) a partir das palavras-chave "escola”, "denúncia”, “condições” e "infraestrutura", sendo descartados todos os registros que não diziam respeito a informações sobre a infraestrutura de escolas de educação básica, ou que fugiam ao recorte temporal estabelecido no ano de 2019.

Após uma primeira análise para composição de um corpus ilustrativo, foram separadas 110 reportagens em mídias locais. Quando contabilizadas o número de escolas (individual ou em grupo) que figuram nas reportagens, chegamos a um conjunto de 458 escolas expostas por falta de infraestrutura adequada. 
Foi realizada, então, uma segunda análise, de onde foram retiradas 03 conclusões de forma/conteúdo assim resumidas: a) só foram encontradas reportagens sobre escolas públicas; b) há reportagens mencionando condições precárias de escolas em todo território nacional; c) as reportagens tanto mencionam escolas isoladas (a condição da escola $\mathrm{X}$ ), quanto um conjunto de escolas (10 escolas da rede $\mathrm{Y}$, ou as escolas da rede Z), o que justifica o número maior de escolas expostas do que de reportagens.

Em uma terceira e última análise, foram identificadas e quantificadas 04 (quatro) categorias de denúncias: 1) deterioração predial; 2) ausência de instalações adequadas ou problemas nas instalações existentes; 3) precarização extrema, e 4) ausência ou funcionamento adequado de programas suplementares

As denúncias sobre deterioração predial são as mais comuns, figurando em 33,6\% das reportagens e evidenciando problemas como a má conservação ou ausência de pintura da escola, infiltrações, telhado com goteiras, piso esburacado, ou obras paradas. A segunda denúncia mais presente, em 28,5\% das reportagens que compuseram a amostra, é a ausência de instalações adequadas ou problemas nas instalações existentes, tais como ausência de quadra esportiva, biblioteca, e/ou sala de informática, assim como bebedouros que não funcionam, sanitários sem condições de uso, bem como cadeiras e classes quebradas. Um conjunto de 25,5\% reportagens examinadas mostram situações de precarização extrema, com inferências a situações que colocam em risco a vida e a integridade física da comunidade escolar (presença de dois ou mais dos itens: vidros quebrados, fiação exposta, mofo, insetos, riscos de desabamento...). Por fim, a ausência ou funcionamento adequado de programas suplementares como merenda, transporte escolar e/ou livro didático (Art. 208, inciso VII, BRASIL, 1988), aparece em 10,2\% das reportagens.

As denúncias apresentadas, nas reportagens examinadas, ainda que cumpram uma função ilustrativa, trazem consigo um olhar sobre ausências, lacunas, faltas... sobre o que não pode ser consentido em uma realidade escolar, sobretudo por vilipendiar de crianças e adolescentes o direito a frequentar um espaço público com o mínimo de dignidade.

\section{Em defesa do direito à qualidade na escola pública}

$\mathrm{Na}$ esfera nacional, diversas legislações sublinham o direito à educação, decorrentes, sobretudo e contemporaneamente, da Constituição Federal de 1988. A educação é arrolada como o primeiro dos dez direitos sociais apresentados no artigo $6^{\circ}$ da mesma Carta Magna: "São direitos sociais a educação, a saúde, a alimentação, o trabalho, a moradia, o lazer, a segurança, a previdência social, a proteção à maternidade e à infância, a assistência aos desamparados, na forma desta 
Constituição" (Redação dada pela Emenda Constitucional no 64, de 04 de fevereiro de 2010). Além de merecer uma seção própria, no âmbito do Capítulo III - Da Educação, da Cultura e do Desporto (BRASIL, 1988).

O Brasil, como Estado democrático de direito, segue a tendência internacional de garantir, legalmente, o direito à educação, pois

Hoje, praticamente, não há país no mundo que não garanta, em seus textos legais, o direito de acesso, permanência e sucesso de seus cidadãos à educação escolar básica. Afinal, a educação escolar é uma dimensão fundante da cidadania e tal princípio é indispensável para a participação de todos nos espaços sociais e políticos e para (re) inserção qualificada no mundo profissional do trabalho (CURY, 2007, p. 484).

Coadjuvantes à Constituição Federal, tanto a Lei de Diretrizes e Bases da Educação Nacional quanto o Estatuto da Criança e do Adolescente, ratificam este direito. No art. $5^{\circ}$. da LDB 9.394, de 20 de dezembro de 1996, é informado que a educação reside na esfera dos direitos, sendo que "o acesso ao ensino fundamental é direito público subjetivo", além de aludir, no artigo anterior, como o dever do Estado para com a educação deverá ser efetivado.

Da mesma forma, o Estatuto da Criança e do Adolescente / ECA (Lei nº 8.069/90), ao regulamentar o artigo 227 da Constituição Federal e servir de mecanismo para assegurar à criança e ao adolescente direitos básicos, como a vida, a saúde e a educação, contribuiu de forma indelével para o reconhecimento da criança como cidadã e o dever do Estado em relação à educação. Dando um passo a mais na direção da garantia de padrões de qualidade mínimos para a consecução específica do direito à educação, o ECA informa “o direito dos pais ou responsáveis ter ciência do processo pedagógico, bem como participar da definição das propostas educacionais" (Art.53, parágrafo único).

O Plano Nacional de Educação - Lei 13.005/2014 -, que cumpre o art. 214 da Constituição Federal expõe como uma de suas diretrizes, a "II - universalização do atendimento escolar" (Art. $2^{\circ}$ ), que corrobora com a perspectiva do direito à educação.

Todavia, parece que o Brasil, historicamente, tem logrado mais êxito em normatizar, juridicamente, o direito à educação, encontrando certa dificuldade em transpor tal direito da base legal para a prática cotidiana, desvelando um paradoxo que implica, 
de um lado, a presença de um ordenamento jurídico como a LDB, capaz de encaminhar os processos educacionais para os princípios e fins da educação nacional (art. 206), com base nos fundamentos democrático-republicanos (art. $1^{\circ}$ ). Mas, de outro lado, a recorrente assinalação de metas universalistas, não efetivadas com a proclamação reiterada do direito à educação escolar obrigatória e gratuita do ensino fundamental e apoiada na vinculação orçamentária, evidencia o quanto de dívida social se tem a resgatar, em função do regime escravocrata vigente no país até 1988, e dos regimes socialmente excludentes que lhe seguiram (CURY, 2016, p. 583).

A redundância e a repetição, nas citações legais que amparam o entendimento da educação como um direito, também objetiva constituir um mecanismo de legitimação e proteção ao direito à educação, tendo em vista que:

A declaração e a garantia de um direito tornam-se imprescindíveis no caso de países, como o Brasil, com forte tradição elitista e que tradicionalmente reservam apenas às camadas privilegiadas este bem social. Por isso, declarar e assegurar é mais que uma proclamação solene. Declarar é retirar do esquecimento e proclamar aos que não sabem, ou esqueceram, que eles continuam a ser portadores de um direito importante. Disso resulta a necessária cobrança deste direito quando ele não é respeitado (CURY, 2002, p.259).

Reconhecer, referendar, reafirmar, lembrar, proclamar, divulgar, estudar, discutir, resenhar, resumir, alardear e pesquisar os indicativos legais seria, pois, mais do que verbalizações, mas constituiriam estratégias de cobrança e vigilância em relação à expectativa e ação na obtenção do direito à educação...

a realização das expectativas quanto à efetivação desse direito expresso em lei, entra em choque com as adversas condições sociais de funcionamento da sociedade. Dessa forma, o direito declarado na legislação é muito significativo, mas não garante a sua efetivação. Portanto, para que se possa entender a educação como um "direito", deve-se compreendê-lo como eixo principal das políticas propostas, pois é importante considerar que a partir das necessidades sociais exigem-se formas para que o direito seja incorporado ao contexto social (CURY, 2002, p. 252).

Sucede, entretanto, que declarações e leis concorrem para estabelecer a universalização do acesso à educação como uma meta. Todavia, na iminência de atingir-se esta meta, faz-se necessário haver outra ambição em relação à educação: a defesa não apenas do acesso, mas de igual forma o sucesso nos bancos escolares e este não depende apenas da declaração de um direito, mas de sua garantia junto ao Estado.

Isto porque o direito à educação é, historicamente, relativamente, recente e característico de movimentos populares que reorganizam concepções no seio do processo social e instauram novas possibilidades de inserção de sujeitos na cidadania. 
O direito à educação como um direito expresso e declarado em lei é recente e remonta ao final do século XIX e início do século XX [...] Ele é um produto dos processos sociais levados adiante pelos segmentos de trabalhadores que viram nele um meio de participação na vida econômica, social e política. (CURY, 2016, p. 569).

No Brasil, se a educação emerge como um direito constitucional, é possível entender que a subtração deste direito é inconstitucional. Ora, com propriedade. pode-se indagar se a falta de investimentos, o abandono, o descuido, o desleixo, o descaso para com a educação pública também poderia receber a classificação de ato inconstitucional. Isto porque "a importância da educação para o processo de construção da democracia, no país, sempre foi muito enfatizada, mas não necessariamente efetivada" (CURY, 2016, p. 583).

Concorrem, para tal situação, em grande medida, as ideias e representações sociais vinculadas à cultura política, razão pela qual, no Brasil - e em outros países com heranças coloniais -, o direito à educação

conviveu e convive com imensas desigualdades sociais. Neles, à desigualdade se soma a herança de preconceitos e de discriminações étnicas e de gênero incompatíveis com os direitos civis. Em muitos destes países, a formalização de conquistas sociais em lei e em direito não chega a se efetivar por causa desses constrangimentos herdados do passado e ainda presentes nas sociedades (CURY, 2002b, p. 256-257).

Imaginemos um aluno que está devidamente matriculado em uma escola, cujo prédio apresenta uma infraestrutura inadequada e mesmo perigosa. O direito à educação está garantido. Porém, o direito ao bem-estar, à saúde e à aprendizagem estão seriamente ameaçados. Um aluno com vaga garantida em uma escola cujo assoalho apresenta condições precárias tem o seu direito à educação garantido. Mas, e a dignidade da pessoa humana como fundamento constitucional (Art. $1^{\circ}$, inciso III, Constituição Federal de 1988), não estaria associada a uma condição mínima de segurança, na escola? Além do que a segurança na escola não seria condição intrínseca para uma aprendizagem de qualidade?

A legislação brasileira insta que a educação seja ofertada com alguma qualidade pois, dentro do art. $4^{\circ}$ da LDB 9.394/96, consta a educação como direito do cidadão à educação e um dever do Estado em atendê-lo mediante 'oferta qualificada'.

$\mathrm{E}$ os direitos não podem ser mitigados, mas fortalecidos no movimento histórico. Referendados e problematizados em relação ao próprio conceito. Nesta direção, Boto alerta que “os direitos nascem e se desenvolvem, não por nossa disponibilidade pedagógica, mas, essencialmente, por conjunturas históricas de formações sociais concretamente dadas" (BOTO, 2005, p.779). 
Além disso, ao longo dos anos, as escolas foram compelidas pelo contexto a assumir o papel de centros culturais dos bairros, para onde acorrem as diferentes manifestações culturais possíveis na realidade local, tais como apresentações teatrais, festivais, festas comunitárias, cursos profissionalizantes, clubes de mães, etc...

Dentro desta perspectiva, a escola legitima a comunidade, referencia, aglutina. A escola, também, colabora na organização familiar e comunitária, adensando princípios que permitam a consecução da cidadania. Portanto, quanto maior a inserção da escola, na vida comunitária, igualmente maiores as possibilidades de cidadania.

$\mathrm{Na}$ ausência de políticas sociais que atendam a necessidades como saúde e lazer, nos bairros e vilas da cidade, a escola passa a ser o espaço indicado para o suprimento de tais lacunas. Não que a escola tenha obrigação de assumir tarefas assistencialistas. Todavia, uma escola não pode dar de ombros a comunidades que estão no limite da linha da pobreza, encontrando na escola uma estrutura de auxílio. É a presença do Estado, a legitimação do espaço público.

Se o acesso à escola pública está, na medida, garantido através da ampliação da oferta, considerando políticas como construção de novas escolas e salas de aula; aquisição de mobiliário; estabelecimento de convênios e parcerias público-privadas; efetivação e ajustes do regime de colaboração entre os sistemas de ensino, o mesmo (ainda) não se pode dizer da permanência e do sucesso na escola pública.

Considerando que a tríade acesso/permanência/ sucesso pode caracterizar-se como um dos indicadores do grau de qualidade da educação, fazer o enfrentamento do que nos separa da permanência e do sucesso maciço nos bancos escolares é um desafio que se instaura para além do (importante) debate teórico, pois "para ser efetiva na promoção do aprendizado de seus alunos, a escola deve usufruir de determinadas condições em relação a seus profissionais, sua infraestrutura física e seu projeto pedagógico" (SOARES, 2016, p.145).

O sucesso, nos bancos escolares públicos, ainda é uma meta a ser perseguida e que requer um empenho em torno de políticas como: gestão democrática da educação; investimento na formação docente, tanto inicial quanto continuada; estudo e adoção de metodologias de ensino diferenciadas, etc... $\mathrm{Na}$ verdade, o acesso à escola é a primeira face do direito, sendo complementada, obrigatoriamente, pelo sucesso escolar (correção de fluxo, políticas de avaliação e currículo, etc...). 
Nossa cidadania educacional está longe de ser um exemplo. Convivemos com milhões de crianças fora da escola ou presentes na escola, mas fora da idade apropriada. Avançamos muito nesse campo, mas enquanto houver uma criança sem escola ou fora da idade adequada, o direito de todos e o dever do Estado não terão se consubstanciado. Temos milhões de jovens e adultos que não tiveram a oportunidade de entrar na escola ou dela tiveram que se evadir mais cedo, por condições de sobrevivência ou por repetência. A educação infantil e o ensino médio ainda são privilégio (CURY, 2016, p. 569).

Se uma declaração é, etimologicamente, aquilo que afiançamos, que afirmamos, que confessamos, declarar a educação como um direito humano e tratá-la de forma menor é, no mínimo, contraproducente, pois o foco da discussão quando o direito à educação é vilipendiado, não é apenas o direito ao banco escolar, mas a um referencial de cidadania que vai muito além dos mesmos bancos.

Por isso, declarar e assegurar é mais do que uma proclamação solene. Declarar é retirar do esquecimento e proclamar aos que não sabem ou se esqueceram que somos portadores de um direito importante. Declarar e assegurar, sob esse enfoque, resultam na necessária cobrança de quem de direito (dever) e na indispensável assunção de responsabilidades por quem de dever (direito) em especial quando ele não é respeitado (CURY, 2007, p. 485).

Nesta direção, “a infraestrutura é um fator que compõe a oferta educativa (insumo) e, ao mesmo tempo, um fator mediador para o ensino e aprendizagem (processo), sendo um atributo para a garantia do direito à educação" (ALVES; XAVIER, 2019, p.67). Portanto, denunciar, apontar, provocar, dialogar, discutir compõem, pois, os verbos atinentes ao estabelecimento de uma nova meta: a educação pública para todos, mas, com igual qualidade para todos, o que inclui, também, a infraestrutura dos espaços escolares.

\section{Considerações finais}

O tema da educação como um direito ainda figura na ordem do discurso, mas, pelo que se depreende da análise do material empírico coletado, com um grande fosso em relação às questões práticas, o que permite insistir no argumento de que não basta colocar todos na escola para alcançar a garantia desse direito.

Assim, o texto parte da retomada de pesquisa conduzida pela UNESCO (ALVES; XAVIER 2019), discutindo alguns dados apresentados na referida pesquisa e, também, em reportagens amostrais sobre a infraestrutura das escolas brasileiras.

A consecução de um direito não está descolada de condições contextuais que possam garantir esse direito efetivamente, para além de declarações. Para que o direito se efetive, é preciso 
contemporizar a retórica e firmar-se na ação, assegurando o direito à educação de qualidade para além do plano das intenções.

Nesta linha de raciocínio, a administração pública se, discursivamente, prima pela educação, merece ser subsidiada e incentivada a movimentar ações e políticas efetivas que garantam uma educação qualitativa, de fato, conjecturando seriamente possibilidades para a educação como um direito pleno. Todavia, parece haver em nosso país - em alguns contextos -, um hiato entre a intenção e a ação. A existência de tal hiato, seguramente, não é um problema de ordem filosófica, mas de ordem política.

Resta comprometer esforços para materializar políticas públicas que considerem a educação como um direito, mas não qualquer educação. Prédios com condições apropriadas de higiene, segurança e mobiliário; professores bem preparados e adequadamente remunerados; democratização da gestão escolar; garantia de padrões suficientes de aprendizagem para todos os alunos são, por fim, indicadores mínimos da qualidade na educação, sem os quais o propalado direito passa a ser apenas um dado numérico de um discurso proselitista.

\section{Agradecimentos:}

Agradecemos o apoio financeiro do Conselho Nacional de Desenvolvimento Científico e Tecnológico - CNPq.

\section{Referências}

ALVES, Maria Teresa Gonzaga; XAVIER, Flavia Pereira. (Coord.). Qualidade da infraestrutura das escolas públicas do ensino fundamental no Brasil - indicadores com dados públicos e tendências de 2013, 2015 e 2017. - Brasília: UNESCO, 2019. 122 p.

BID/Banco Interamericano de Desarrollo División de Educación. Notas Técnicas: Infraestructura Escolar y Aprendizajes en la Educación Básica Latinoamericana: Un análisis a partir del SERCE. Jesús Duarte Carlos Gargiulo Martín Moreno. Maio de 2011. Disponível em [http://idbdocs.iadb.org/wsdocs/getdocument.aspx?docnum=36201660]

BOTO, Carlota. A educação escolar como direito humano de três gerações: identidades e universalismos. Educação \& Sociedade, Campinas, SP, CEDES, n.92, v.26, Número Especial, 2005.

BRASIL. Presidência da República. Casa Civil. Subchefia para Assuntos Jurídicos. Constituição da República Federativa do Brasil, 1988. Disponível em:

http://www.planalto.gov.br/ccivil_03/constituicao/constituicao.htm. Acesso em: 10 ago. 2019. 


\section{Dialogia}

ESQUINSANI, Rosimar Serena Siqueira. Quando o acesso é o menor dos problemas: o direito ao espaço escolar de qualidade

BRASIL. Presidência da República. Casa Civil. Subchefia para Assuntos Jurídicos. Lei 9. 394. Estabelece as diretrizes e bases da educação nacional. Brasília: Casa Civil, 1996. Disponível em: http://www.planalto.gov.br/CCIVIL_03/leis/L9394.htm. Acesso em: 10 ago. 2019.

BRASIL, Sinopse Estatística da Educação Básica de 2019 (http://inep.gov.br/sinopsesestatisticas-da-educacao-basica), 2020.

BRASIL. Presidência da República. Casa Civil. Subchefia para Assuntos Jurídicos. Lei 13.005, de 25 de junho de 2014. Aprova o Plano Nacional de Educação - PNE e dá outras providências. Disponível em: http://www.planalto.gov.br/ccivil_03/_Ato2011-2014/2014/Lei/L13005.htm. Acesso em: 10 ago. 2019.

CURY, Carlos Roberto Jamil. A Educação Básica no Brasil. Educação \& Sociedade, Campinas, v. 23, n. 80, p.169-201. Set-dez., 2002.

CURY, Carlos Roberto Jamil. Direito à educação: direito à igualdade, direito à diferença. Cadernos de Pesquisa, São Paulo, n. 116, p. 245-262. 2002b

CURY, Carlos Roberto Jamil. A gestão democrática na escola e o direito à educação. Revista Brasileira de Política e Administração da Educação. v.23, n.3, p. 483-495, set./dez. 2007

CURY, Carlos Roberto Jamil. A Educação como Desafio na Ordem Jurídica. In: $\mathbf{5 0 0}$ anos de Educação no Brasil, p. 567-584. Org: LOPES, Eliane Marta Teixeira; FARIA FILHO, Luciano Mendes e VEIGA, Cynthia Greive - 5.Ed.; 2.reimp - Belo Horizonte: Autêntica, 2016.

FRANÇA, D.M.C. (et. all). Implementação do plano de ações articuladas em municípios da Paraíba. IN: FARENZENA, N. (org.). Implementação de Planos de Ações Articuladas Municipais: Uma avaliação em quatro estados brasileiros. Pelotas: Ed. Gráfica Universitária/UFPEL, 2012, p. 65-90.

OLIVEIRA, Romualdo Portela de; ARAUJO, Gilda Cardoso de. Qualidade do ensino: uma nova dimensão da luta pelo direito à educação. Revista Brasileira de Educação. 2005, n.28, pp. 5-23.

SOARES, José Francisco. O direito à educação no contexto da avaliação educacional. Em Aberto, Brasília, v. 29, n. 96, p. 141-152, maio/ago. 2016

SORDI, M.R.L.; LUDKE, M. Da avaliação da aprendizagem à avaliação institucional: aprendizagens necessárias. Avaliação, Campinas; Sorocaba, v.14, n. 2, p.313-336, jul. 2009.

Recebido em: 31 mar. 2020/ Aprovado em: 25 jun. 2020

Cite como

(ABNT NBR 6023:2018)

ESQUINSANI, Rosimar Serena Siqueira. Quando o acesso é o menor dos problemas: o direito ao espaço escolar de qualidade. Dialogia, São Paulo, n. 35, p. 22-35, maio/ago. 2020. Disponível em: https://doi.org/10.5585/dialogia.n35.16944. 


\section{Dialogia}

ESQUINSANI, Rosimar Serena Siqueira. Quando o acesso é o menor dos problemas: o direito ao espaço escolar de qualidade

\section{American Psychological Association (APA)}

Esquinsani, R. S. S. (2020, maio/ago.). Quando o acesso é o menor dos problemas: o direito ao espaço escolar de qualidade. (2020, maio/ago.). A produção de vídeo por pessoas em sofrimento psíquico. Dialogia, São Paulo, 35, p. 22-35.

https://doi.org/10.5585/dialogia.n35.16944. 